\title{
Biología e inmunopatogénesis del carcinoma espinocelular y el basocelular
}

Biology and immunopathogenesis of skin cancer

\author{
Ana María Mejíaํ, Margarita María Velásquez ${ }^{2}$ \\ 1. Médica, residente de primer año, Sección de Dermatología, Facultad de Medicina, Universidad de Antioquia, Medellín, Colombia. \\ 2. Médica dermatóloga; profesora, Sección de Dermatología, Grupo de Investigación Dermatológica, CIDERM, Universidad de Antioquia, Medellín, Colombia.
}

\section{Resumen}

El cáncer de piel es el tipo de cáncer más frecuente. El cáncer de piel no melanoma incluye el carcinoma basocelular y el carcinoma espinocelular. Debido a que la mayoría son poco agresivos y a que algunos se resecan sin estudio histopatológico, existe un subregistro. Esta revisión se enfoca en los aspectos más importantes de la biología y la inmunopatogénesis del carcinoma basocelular y del espinocelular.

Los factores de riesgo incluyen la exposición a los rayos ultravioleta, los fototipos 1 y 2, tener el cabello y los ojos claros, la ascendencia europea y el vivir en aéreas tropicales, entre otros. La patogénesis es compleja e involucra varias vías, entre las cuales están la apoptosis, las alteraciones del gen p53, las especies reactivas del oxígeno, el virus del papiloma humano, la inmunosupresión externa (medicamentos inmunosupresores) y la ocasionada por el sol.

PALABRAS CLAVE: carcinoma de piel tipo no melanoma, carcinoma basocelular, carcinoma espinocelular, apoptosis, vía hedgehog (o vía para activación de factores y transcripción hedgehog).

\section{Summary}

Skin cancer is the most common type of cancer. The non-melanoma skin cancer includes basal cell carcinoma and squamous cell carcinoma. Since most of them are not aggressive and some are resected without any histopathological study, there is underreporting. This review focuses on the most important aspects of the biology and immunopathogenesis of basal cell and squamous cell carcinoma.

Risk factors include exposure to ultraviolet rays, skin type 1 and 2, having light eyes and hair, European descent and living in tropical areas, among others. The pathogenesis is complex and involves different routes such as apoptosis, gene p53 alterations, reactive oxygen species, human papilloma virus, external immunosuppresion (immunosuppressive drugs) and that caused by sun exposure.

KEY WORDS: Non-melanoma skin cancers, basal-cell carcinoma, squamouscell carcinoma, apoptosis, hedgehog pathway.

\section{Correspondencia:}

Ana María Mejía

Email:

aname93@hotmail.com

Recibido: 20 de diciembre de 2012. Aceptado: 15 de marzo de 2013.

No se reportan conflictos de intereses. 


\section{Introducción}

Los carcinomas de piel se dividen según el origen histológico, en carcinomas de tipo melanoma, que se derivan de los melanocitos, y los carcinomas de piel no melanoma, en los que se incluyen los linfomas cutáneos, el tumor de células de Merkel, los tumores de los anexos, el carcinoma basocelular y el carcinoma espinocelular. Estos dos últimos son los más importantes ${ }^{1}$, pues comprenden alrededor del $90 \%$ de todos los cánceres de piel y, por lo general, cuando se habla de carcinomas de piel no melanoma solamente se incluyen a estos dos$^{2}$.

\section{Definición}

El carcinoma basocelular es el más común de todos los carcinomas de piel no melanoma; su morfología es similar al estrato basal de la epidermis y produce invasión local con destrucción y daño tisular. Es de crecimiento lento y tiene poco riesgo de producir metástasis. En la gran mayoría de los casos, el carcinoma basocelular aparece de novo, es decir, no se origina sobre otras lesiones precursoras. Entre las condiciones precursoras del carcinoma basocelular están la radiodermitis, el nevus sebáceo de Jadassohn y el xeroderma pigmentoso ${ }^{1,3}$.

El carcinoma escamocelular es el segundo en frecuencia; también originado en la capa basal de la epidermis, aparece en áreas expuestas y no expuestas a la luz, como los genitales, y puede tener lesiones precursoras como las queratosis actínicas, las quemaduras y las úlceras crónicas. Ocasionalmente, puede producir metástasis ${ }^{3}$ y cuando estas ocurren, comprometen principalmente los ganglios linfáticos regionales y son detectadas uno a tres años después del diagnóstico inicial ${ }^{2,4,5}$.

\section{Epidemiología}

El cáncer de piel es el tipo de cáncer más común; representa casi la mitad de los cánceres en los Estados Unidos y se estima que su incidencia en este país es, aproximadamente, $1^{\prime}$ ooo.ooo de casos por año; de estos, del 20 al $30 \%$ son carcinomas espinocelulares ${ }^{6}$.

$\mathrm{Su}$ incidencia varía en los diferentes lugares del mundo de acuerdo con los factores que influyen en su aparición, como la cercanía con la línea ecuatorial (a mayor cercanía, mayor riesgo) y las costumbres de las personas para exponerse al sol, entre otros ${ }^{1}$.

En general, los carcinomas de piel no melanoma no se registran en las estadísticas de cáncer ${ }^{6} \mathrm{y}$ esto hace que su frecuencia se subestime; la incidencia también aumenta con la edad, siendo más prevalente en mayores de 60 años ${ }^{1}$.

Australia ha tenido la mayor incidencia de carcinoma basocelular en el mundo: 1.041 por 100.000 hombres y 745 por 100.000 mujeres 7,8

En nuestro país, según el reporte del Instituto $\mathrm{Na-}$ cional de Cancerología en un artículo del 2002 sobre 4.990 casos de cáncer nuevo, el tumor más frecuente en las mujeres fue el de cuello uterino ( $23 \%)$, seguido por el de mama (19\%) y el de piel $(11,8 \%)$. En hombres, excluyendo el de piel, el cáncer de próstata tuvo mayor frecuencia $(13,5 \%)^{9}$. También, en un estudio retrospectivo de Sanclemente, et al., en 1999, en el que se evaluaron las causas más frecuentes de consulta dermatológica en diferentes centros médicos de Medellín, se reportó que el cáncer de piel de tipo no melanoma era la causa más frecuente de consulta en el Hospital Universitario San Vicente de Paúl, 9 \% del total: carcinoma basocelular, $7 \%$, y carcinoma espinocelular, 2,\%; en el Hospital Pablo Tobón Uribe fue la novena causa: carcinoma basocelular, 0,9 \%, y otros tumores malignos de piel, 3,9, $\%{ }^{10}$.

Sánchez, et al., llevaron a cabo un estudio observacional descriptivo de pacientes con diagnóstico confirmado de carcinoma basocelular que acudieron al Centro Dermatológico Federico Lleras Acosta en el 2008, y encontraron que el promedio de edad fue de 65,1 años (rango, 30 a 95); las mujeres eran el 61\% de las muestras (123/203); $15 \%$ vivía en el área rural después de los 30 años; 50 \% tenía alguna ocupación laboral al aire libre antes de los 15 años, $45 \%$ entre los 15 y 30 años y $41 \%$ después de los 30 años, las actividades relacionadas con el campo eran las más frecuentes. El 76,4 \% de los sujetos declaró haber practicado un deporte antes de los 15 años, el $42 \%$, entre los 15 y 30 años, y el 35,5\%, después de los 30. El $86 \%$ de los tumores se localizaron en el rostro $(n=174)$; de estos, la nariz fue la más afectada $(n=58)$, seguida de la mejilla $(n=43)$ y la frente $(n=18)$. Según el fototipo, $5 \%(\mathrm{n}=11)$ eran del fototipo I, $69 \%$ $(\mathrm{n}=141)$, del fototipo II, $22 \%(\mathrm{n}=43)$, del fototipo III y $4 \%$ $(\mathrm{n}=8)$ del fototipo IV. Se determinó que el $68 \%(\mathrm{n}=138)$, tenía ojos claros, 33,5 \% $(\mathrm{n}=6)$ tenía pelo claro $\mathrm{y}$, por último, que se encontraron algunas alteraciones concomitantes, como queratosis actínicas (53\%), lentigos solares en manos y antebrazos (50\%) y poiquilodermia de Civatte (34\%). En este estudio hubo discrepancia en relación con el sexo de lo reportado en otros países, en los cuales hay una relación hombre a mujer de 3 a 2; en este estudio se encontró lo contrario, pero apoya que la radiación ultravioleta es el factor más importante para el desarrollo de carcinoma basocelular ${ }^{11}$.

En el 2011 se realizó una jornada de detección precoz de cáncer de piel en Medellín, con la participación de la Universidad de Antioquia, la Universidad del CES y otros dermatólogos de la ciudad; se citaron 1.265 pacientes, de los cuales, 246 (19,4\%) tuvieron sospecha 


\section{Factores de riesgo}

1. Ojos y pelo claros.

2. Descender de europeos.

3. Vivir en lugares tropicales.

4. Inmunosupresión.

5. Infección por HPV.

6. Químicos: cal, arsénico, psoralenos.

7. Alteraciones genéticas en los genes para la reparación celular.

8. Otros.

TABLA 1.Factores de riesgo.

de lesión maligna o premaligna. A 149 (11,7 \%) se les tomó biopsia, a 55 pacientes de les hizo el diagnóstico clínico de queratosis actínica, 39 de nevus atípico y 3 con ambos diagnósticos. De las biopsias que se practicaron, se diagnosticaron 2 melanomas malignos, 14 carcinomas espinocelulares, 59 carcinomas basocelulares, 15 nevus atípicos, 16 queratosis actínicas, 34 otros nevus y 34 lesiones no malignas ${ }^{12}$.

En el 2005, en la Universidad CES se evaluaron 736 personas mayores de 18 años, de las cuales, $10 \%$ tenía sospecha clínica de lesiones malignas y $13,7 \%$ de lesiones premalignas, y 19,7 \% presentaba algún tipo de alteración producida o agravada por el sol ${ }^{13}$.

El Global Cancer Statistics es un programa que lleva las estadísticas de cáncer en todo el mundo. Sin embargo, al buscar la estadística de cáncer en Colombia se encuentran en este registro todos los cánceres, excepto el de piel de tipo no melanoma, por lo cual una estadística actual de nuestro país de este tipo de cáncer es difícil de obtener ${ }^{14}$.

El bajo riesgo de mortalidad que tienen estos tumores, parece ser una de las principales razones para su subregistro. Sin embargo, se ha visto un aumento en la frecuencia de estos tumores, debido a la migración a lugares cálidos y al incremento del uso de cámaras bronceadoras ${ }^{15}$.

\section{Factores de riesgo}

En la TABLA 1 se resumen los factores de riesgo. Los carcinomas de piel no melanoma afectan principalmente a las personas de piel y ojos claros, las cuales corresponden, principalmente, a los fototipos de piel I y II con base en la clasificación de Fitzpatrick (TABLA 2), que descienden de europeos. Se localiza especialmente en
Clasificación de Fitzpatrick

Tipo I: piel blanca que se quema con facilidad y no se broncea.

Tipo II: piel blanca que se quema con facilidad y se broncea mínimamente.

Tipo III: piel ligeramente morena que se quema moderadamente y se broncea gradualmente.

Tipo IV: piel morena que se quema mínimamente y se broncea bien.

Tipo V: piel muy morena que difícilmente se quema y se broncea intensamente.

Tipo VI: piel negra que no se quema y de profunda pigmentación.

TABLA 2. Clasificación de Fitzpatrick.

áreas expuestas a la luz, lo que nos indica que los rayos ultravioleta están involucrados en su desarrollo.

Los rayos ultravioleta (UV) se dividen en UVC (200-280 $\mathrm{nm})$, UVB $(280-320 \mathrm{~nm})$ y UVA (320-400 $\mathrm{nm})$. De estos, solo los UVB y los UVA están en el medio ambiente, ya que los UVC son absorbidos eficientemente por la capa de ozono. Los UVB penetran en la epidermis o en la parte superficial de la dermis, mientras que los UVA penetran en las capas profundas de la dermis ${ }^{16}$. De estos rayos, el espectro B (290-320 nm) es el que está más involucrado en su patogenia. La duración de esta exposición es diferente en ambos tipos de tumores; mientras que la exposición continua favorece la aparición de carcinoma espinocelular, la exposición intermitente durante las actividades recreacionales favorece la aparición del carcinoma basocelular ${ }^{7}$.

Se ha encontrado también relación entre productos químicos, como la cal, el arsénico y los psoralenos, y el incremento de cáncer de piel no melanoma. El cigarrillo se ha relacionado principalmente con el carcinoma espinocelular ${ }^{7}$. El uso de cámaras bronceadoras se ha relacionado con el incremento de cáncer de piel ${ }^{15}$.

La inmunosupresión se ha relacionado con el aumento en la frecuencia de cáncer de piel; esto se ha visto en los pacientes con trasplante, en quienes el grado de inmunosupresión se correlaciona con el riesgo de desarrollar cáncer ${ }^{17}$.

Hay varios factores genéticos que predisponen a múltiples lesiones de carcinomas basocelulares; entre ellos se encuentran el síndrome de Bazex-Dupre-Christol, el síndrome de Gorlin y el síndrome de Rombo. También son factores de riesgo el xeroderma pigmentoso, el albinismo y la epidermodisplasia verruciforme ${ }^{18}$. 


\section{Carcinoma basocelular}

Según sus características histológicas y su profundidad, este cáncer se divide en nodular (6o \%), superficial (25\%), micronodular (15\%) y morfeiforme infiltrativo ( $2 \%)$; los dos primeros son los subtipos no agresivos, mientras que los tipos morfeiforme y micronodular son los más agresivos y están asociados con alto riesgo de recurrencia local7.

\section{Carcinoma escamocelular}

Este cáncer se inicia con una lesión precursora y la más frecuente es la queratosis actínica; algunos la consideran como un carcinoma in situ que solo compromete la epidermis. Otros precursores son las úlceras crónicas, los trayectos fistulosos de las osteomielitis, la radiodermitis crónica, la leucoplasia oral, la queilitis actínica, la epidermodisplasia verruciforme y la papulosis bowenoide. Los carcinomas in situ son la eritroplasia de Queyrat y la enfermedad de Bowen, los cuales pueden progresar a carcinoma espinocelular invasivo ${ }^{19}$.

\section{Patogénesis}

La radiación ultravioleta causa daño directo al ADN y al ARN, haciendo que se formen enlaces covalentes entre las pirimidinas adyacentes y permitiendo la producción de fotoproductos mutágenos, como los dímeros de ciclopiridina y pirimidina-pirimidina que, generalmente, cambian citocina por timina ya sea en monómero o en dímeros C-T o CC-TT. La radiación ultravioleta A es menos mutagénica que la UVB; además, causa daño indirecto por mecanismos de estrés de fotooxidación que resulta en la formación de especies reactivas de oxígeno, las cuales interactúan con los lípidos, las proteínas y el $A D N$, y generan intermediarios que se combinan con el ADN. Varios sistemas de reparación, como la enzima superóxido dismuta, la catalasa y la peroxidasa de glutatión, entre otros, son necesarios para prevenir el daño de estos premutágenos ${ }^{1,20,21}$

Si no se repara el ADN por parte del p53 ("el guardián del genoma”) o si las células dañadas no son eliminadas por apoptosis, se presenta una proliferación descontrolada y, como consecuencia, la formación de un tumor.

Son varios los mecanismos que intervienen en el desarrollo del cáncer de piel, varios de los cuales se tratan con más profundidad a continuación.

\section{Vía de señalización hedgehog}

El descubrimiento de la mutación del gen ptch (patched) en el brazo largo del cromosoma 9, que codifica la proteína PTCH 1 en los pacientes con síndrome de Gorlin, en quienes se observan múltiples carcinomas basocelulares desde edades muy tempranas asociados a malformaciones esqueléticas y aumento del riesgo de carcinoma de vejiga, permitió identificar la importancia de esta vía en la carcinogénesis humana, ya que involucra al carcinoma basocelular y a otros tumores del tubo neural como el meduloblastoma ${ }^{7}$.

La PTCH 1 es parte de un complejo receptor de la superficie celular que está formado por dos proteínas transmembrana, PTCH 1 y smoothened. La PTCH inhibe la capacidad de la smoothened de transmitir señales a numerosos genes objetivo, incluidos algunos genes como el ptch y el gli, los cuales son factores de transcripción asociados a la familia glioma.

Cuando el factor $\mathrm{HH}$, secretado extracelularmente, se une a la PTCH en el complejo receptor, la smoothened es liberada y la señal es traducida. Esto ocurre mediante una serie de interacciones intracelulares que permiten la activación de los factores de transcripción asociados a la familia glioma (GLI-1, GLI-2 y GLI-3).

El factor GLI-1 siempre permite la activación de la transcripción, mientras que el GLI-2 y el GLI-3 pueden permitir la activación o la supresión.

Los genes blanco incluyen los reguladores del ciclo celular WNT (wingless), el factor transformador de crecimiento beta (TGF-B), la proteína PTCH1 y el factor GLI-1.

Normalmente, la PTCH 1 proporciona una regulación negativa en la vía debido a que se une a la smoothened y la inhibe, al unirse el $\mathrm{HH}$ a la PTCH 1 hace que esta última libere la smoothened permitiendo así que se activen las señales intracelulares para activar los factores de transcripción. La HIP, proteína que interactúa con el $\mathrm{HH}$ y es producida por los factores de transcripción, se une al HH bloqueándola y actúa como un regulador negativo de la vía.

El gen $p t c h$ se ha implicado en el desarrollo de diferentes estructuras, como el tubo neural, el esqueleto, las extremidades, las estructuras cráneo-faciales, la piel y los folículos pilosos en la embriogénesis.

La activación de la vía del $\mathrm{HH}$ favorece la proliferación celular y, si las vías normales de control están alteradas, puede inducir la formación de tumores. El ptch puede influir de modo directo sobre la progresión del ciclo celular ${ }^{22,23}$; se ha observado que el factor $\mathrm{HH}$ antagoniza la función del inhibidor p21 que está encargado de restringir la progresión del ciclo celular, mientras que el ptch restringe la progresión del ciclo celular en la fase G2. 
Por consiguiente, la inactivación del gen $p t c h$ podría producir una progresión aberrante del ciclo celular, ya sea por imitar la señalización del $\mathrm{HH}$, o por pérdida de la inhibición que el ptch hace sobre el ciclo celular, llevando a la formación de tumores, por lo que se conoce a ptch como un gen supresor tumoral.

La alteración en este gen se ha encontrado, como se explicó anteriormente, en el síndrome del Gorlin y, aproximadamente, en el $68 \%$ de los carcinomas basocelulares esporádicos ${ }^{1,19,24,25,26}$. La pérdida de la proteína PTCH1 también se ha reportado como un evento temprano en la patogénesis del carcinoma espinocelular ${ }^{1,22,27}$.

\section{Gen $P_{53}$}

El gen $P_{53}$ codifica la proteína $p_{53}$ conocida como el guardián del genoma y es uno de los genes mutados con mayor frecuencia en los cánceres de humanos ${ }^{28}$.

La activación de este gen lleva a la célula a dos caminos diferentes: la inactivación temporal de la célula y el rearreglo o la activación de una muerte celular por apoptosis.

El $p 53$ se activa cuando hay daño en la integridad celular, expresión inadecuada de oncogenes (MYC y RAS) o daño en el ADN, manteniendo así la integridad del genoma.

En las células normales, el $p_{53}$ tiene una vida corta de 20 minutos, ya que se asocia a la MDM2 (Murine Double Minute Clone 2), una proteína encargada de destruirlo; cuando la célula presenta alteraciones, el $p_{53}$ se libera de la MDM2 y esta dura mayor tiempo, permitiendo así el arreglo de la célula.

La detención de la célula la realiza en la fase G1 del ciclo celular y está producida principalmente por la $\mathrm{CDK} 1$, cinasa dependiente de la ciclina CDKN1A (p21). La CDKN1A también inhibe complejos ciclina-CDK. El p21 evita la fosforilación de la proteína del retinoblastoma, ya que esta proteína cuando está fosforilada es la que se encarga del paso del ciclo celular de Go a G1; de esta manera, detiene el ciclo en Go para permitir su arreglo.

El p53 también induce ciertas proteínas, como la GADD45 (Growth Arrest and DNA-Damage Inducible Gene Number 45) que detiene el crecimiento y el daño del ADN y favorece la producción de MDM2 para facilitar su destrucción ${ }^{29}$.

Si la célula no es reparada entra en senescencia o en apoptosis; en la senescencia hay cambios aún poco claros; parece que hay una alteración en la cromatina y la apoptosis la activa por medio de las proteínas $\mathrm{BAX}^{29}$.

La presencia de mutaciones causadas por la radiación ultravioleta (sustituciones simples o dobles de citocina por timidina en los sitios de pirimidina), indica el importante papel de la radiación ultravioleta en la carcinogé- nesis de la piel y son mutaciones que se han encontrado en el gen $p 53^{7}$. La alteración de este gen se ha encontrado en 44 a $100 \%$ de los carcinomas basocelulares ${ }^{28}$.

Una mutación en la línea germinal en el gen p53, conocida como el síndrome de Li-Fraumeni, predispone al cáncer. Los pacientes con este síndrome no están predispuestos a los cánceres de piel, lo que sugiere que la mutación del p53 no es necesaria para la génesis de este tumor, pero que puede ser un evento secundario después de la iniciación del tumor. Es interesante que las personas que usan bloqueador solar hayan tenido menos mutaciones en $p 53$ en comparación con las que no lo utilizan, lo que sugiere que esta mutación es un evento secundario y no se requiere para el desarrollo del carcinoma basocelular $7,25,30$.

En un estudio en el Hospital Andreas Sygros en Atenas, Grecia, para evaluar la correlación del p 53 con la apoptosis y la proliferación celular en 35 pacientes con carcinomas de piel no melanoma, describieron que $p 53$ solo se podía medir si había mutado, ya que se aumentaba su tiempo de vida media. Los autores concluyeron que el $p_{53}$ era abundante en la mayoría de los carcinomas de la piel examinada, y además, que existió una correlación positiva con la proliferación celular y una negativa con la apoptosis ${ }^{31}$.

De lo anterior se puede inferir que la inactivación del gen supresor de tumores, $p_{53}$, tiene un importante papel en el desarrollo de carcinomas de piel no melanoma. La alteración en este gen es producto de la radiación ultravioleta (sustitución de citocina por timina), lo que induce resistencia a la apoptosis en los queratinocitos y favorece su expansión clonal y la oncogénesis. Se encuentran mutaciones en el $p_{53}$ en, aproximadamente, $50 \%$ de los carcinomas basocelulares y $90 \%$ de los espinocelulares ${ }^{1,32}$.

\section{Apoptosis}

La apoptosis es un tipo de muerte celular que sirve como mecanismo para eliminar las células defectuosas y así prevenir la formación de tumores. En la apoptosis se forman cuerpos apoptóticos que se eliminan con la fagocitosis, evitando una respuesta inflamatoria. Uno de los principales hallazgos en el cáncer de piel es la resistencia a la apoptosis?.

Se describen dos vías para la apoptosis. Una de ellas es la extrínseca, mediada por los receptores de la familia del factor de necrosis tumoral (TNF) (Fas-FasL, TRAIL). El receptor Fas es expresado en diferentes tipos de células, mientras que el FasL es expresado por células del sistema inmunitario como linfocitos $\mathrm{T}$, linfocitos $\mathrm{B}$, macrófagos y células NK (natural killer); la unión de Fas a FasL causa una muerte rápida, induciendo señales para 
EXPRESIÓN DE LOS DIFERENTES LIGANDOS DE MUERTE CELULAR EN PIEL NORMAL, QUERATOSIS ACTÍNICA Y TUMORES DE PIEL

\begin{tabular}{|c|c|c|c|c|c|c|}
\hline \multirow[b]{2}{*}{ Capas de piel } & \multicolumn{2}{|c|}{$\begin{array}{l}\text { Piel protegida de los RUV } \\
\text { radiación UV }\end{array}$} & \multicolumn{2}{|c|}{$\begin{array}{c}\text { Piel expuesta a los RUV } \\
\text { radiación UV }\end{array}$} & \multirow[t]{2}{*}{$\begin{array}{l}\text { Queratosis } \\
\text { actínica }\end{array}$} & \multirow[t]{2}{*}{$\mathrm{CBC} / \mathrm{CEC}$} \\
\hline & Basal & Superiores & Basal & Superiores & & \\
\hline FasL & ++ & + & - & - & - & +++ \\
\hline Fas & - & - & ++ & ++ & ++ & - \\
\hline TRAIL & +++ & + & ++ & + & ++ & +++ \\
\hline TRAIL-R1 & - & +++ & - & ++ & - & - \\
\hline TRAIL-R2 & - & ++ & - & - & NE & - \\
\hline TRAIL-R3 & ++ & $+1-$ & $+/-$ & - & NE & - \\
\hline FLIP & +++ & + & +++ & + & ++ & +++ \\
\hline
\end{tabular}

TABLA 3. Expresión de los diferentes ligandos de muerte celular en piel normal, queratosis actínica y tumores de piel.

reclutar y activar a la procaspasa-8, la cual es una caspasa iniciadora que, a su vez, activará a la caspasa 30 ejecutora? .

La otra vía de la apoptosis es la intrínseca, la cual depende de la mitocondria; cuando hay lesiones en el ADN, se envían señales a la mitocondria que hacen que cambie la permeabilidad de la membrana y permita la salida del citocromo $C$; este se unirá al factor activador proapoptótico (APAF), permitiendo la activación de la caspasa 9 que, a su vez, activa a la caspasa 3. Esta vía es ejecutada por miembros de la familia Bcl-2, que incluye proteínas proapoptóticas, como la Bax y la Bak, y antiapoptóticas, como Bcl-2 y Bcl-xL4,33,34,35.

Estas dos vías tienen en común que activan las caspasas (proteasas de cisteína específica de aspartato). En el humano se han identificado varias caspasas, que comparten secuencias de aminoácidos, y tienen una estructura y un substrato específico, en el cual clivan residuos de acido aspártico. Hay dos familias de caspasas: las iniciadoras de la apoptosis (caspasa 2, 8, 9 y 10) y las ejecutoras de la apoptosis (caspasa 3, 6 y 7). La caspasa 3 parece ser la responsable de la mayoría de los efectos de la apoptosis. Estas tres caspasas ejecutoras son importantes en la división y la degradación de varios sustratos, proteínas diana que participan en el ensamblaje del $\mathrm{ARN}$, la reparación del ADN y las proteínas citosólicas y nucleares ${ }^{7}$.

La apoptosis puede ser regulada por proteínas inhibidoras de las caspasas; otros inhibidores de la apoptosis incluyen la proteína inhibitoria Flice (FLIP) y la survivina ${ }^{4}$.

La mayoría de los cánceres exhiben defectos en los mecanismos de la apoptosis o desarrollan mecanismos para evadirla, lo que lleva a una proliferación no controlada ${ }^{36,37}$.

En la piel protegida del sol, los receptores FasL y TRAIL (ligando inductor de apoptosis relacionado con el factor de necrosis tumoral) son expresados principalmente en las capas basales y menos en las capas superiores; mientras que el Fas está ausente en la epidermis, los receptores TRAIL R1 y TRAIL R2 no son expresados en la capa basal, pero sí en la superiores; los TRAIL R3 y la proteína FLIP son fuertemente expresados en la basal, pero débilmente en las capas superiores.

En la piel expuesta al sol, el receptor FasL está completamente ausente, mientras que el Fas, el TRAIL y la FLIP están presentes, y el TRAIL $R$ es menos expresado. Cuando ya se da la formación tumoral, el FasL y el TRAIL se expresan fuertemente, mientras que el TRAIL $R$ no, al mismo tiempo que se aumentan las proteinas Bcl-2 y FLIP. La expresión del FasL activa la apoptosis de los linfocitos infiltrantes, permitiendo la evasión de la respuesta inmunitaria y favoreciendo el crecimiento neoplásico ${ }^{4}$ (TABLA 3).

\section{Radicales libres de oxígeno}

Los radicales libres son todas aquellas especies químicas, cargadas o no, que en su estructura atómica presentan un electrón no apareado o impar en el orbital externo que les da una configuración espacial generadora de gran inestabilidad; además, tienen la capacidad de aparearse, por lo que son muy reactivos.

Estos radicales intentan tomar un electrón de las moléculas estables, con el fin de alcanzar su estabilidad 
electroquímica. Las principales especies reactivas del oxígeno o sustancias prooxidantes son el radical hidroxilo, el peróxido de hidrógeno y el anión superóxido. Normalmente se producen sustancias que los neutralizan, como la enzima superoxido dismuta, la catalasa y la peroxidasa de glutatión, y de esta manera, se evita el daño que puedan ocasionar ${ }^{38}$.

La radiación ultravioleta genera estrés por oxidación de la piel, produciendo peroxidación de lípidos e hidroperóxidos en el ADN; para esto, la enzima glutatión $S$ transferasa defiende contra este tipo de daño. Las alteraciones de esta enzima están relacionadas con varios tipos de cáncer, incluidos los carcinomas de piel no melanoma ${ }^{739}$.

\section{Carcinomas de piel no melanoma en pacientes con trasplante}

Las personas con trasplantes desarrollan tumores malignos de piel con mayor frecuencia, que son más agresivos y producen más metástasis, lo que indica que la inmunosupresión favorece la disminución de los mecanismos de vigilancia. La incidencia se incrementa con la duración de la inmunosupresión y con la dosis de los medicamentos; por ejemplo, los pacientes con trasplante cardiaco tienen mayor inmunosupresión y desarrollan más tumores que los receptores de otros trasplantes (por ejemplo, de hígado), quienes reciben inmunosupresores a dosis más bajas ${ }^{40}$.

La media del intervalo entre el trasplante y el diagnóstico de cáncer de piel, es de ocho años para los pacientes que reciben el trasplante antes de los 40 años de edad y de tres años para quienes reciben el trasplante después de esa edad ${ }^{41}$.

Normalmente, la relación de los carcinomas basocelulares frente a los espinocelulares es de $4 \mathrm{a} 1$; en estos pacientes esta relación se invierte, siendo de 4 carcinomas espinocelulares por 1 carcinoma basocelular ${ }^{41}$.

En cuanto a la incidencia de carcinoma basocelular en pacientes con trasplante, existen reportes controversiales en la literatura científica; algunos autores afirman que no se incrementa ${ }^{7}$, mientras que otros reportan que el carcinoma basocelular puede aumentar hasta 10 veces y, el carcinoma espinocelular, de 65 a 265 veces $^{41}$.

Fortina, et al., en un estudio en el Instituto Dermatológico en Padua, Italia, evaluaron el riesgo de desarrollar carcinomas de piel no melanoma en 230 pacientes con trasplante de corazón, en relación con la dosis acumulada del inmunosupresor. Estos autores calculan que, a los 10 años del trasplante, uno de cada cinco pacientes desarrolla carcinoma espinocelular y, uno de cada ocho, carcinoma basocelular ${ }^{17}$.

Las lesiones se localizan principalmente en las áreas expuestas a la luz, particularmente en la cara (alrededor de la boca) y en el dorso de las manos. Los hallazgos clínicos son generalmente similares a los encontrados en los pacientes inmunocompetentes, pero las lesiones generalmente son múltiples ${ }^{42,43}$.

Los inmunosupresores pueden tener un efecto directo en la producción de carcinomas. La ciclosporina y el tacrolimus, en particular, han sido implicados en el incremento de este riesgo. La administración de inhibidores de la calcineurina se ha implicado en la propensión al desarrollo de cáncer de piel, ya que previene la defosforilación del NFAT, un factor de transcripción necesario para la reparación del ADN y el BAD (promotor de muerte celular), agonista de la muerte celular. Los inhibidores de la calcineurina también inhiben la liberación de citocromo $\mathrm{C}$, de esta manera evaden la apoptosis ${ }^{44}$. La azatioprina aumenta la sensibilidad del ADN a la radiación ultravioleta ${ }^{45}$.

En estos pacientes inmunosuprimidos, al igual que en los inmunocompetentes, el principal factor de riesgo son los rayos ultravioleta; los de piel clara son más propensos que los de piel oscura ${ }^{36,46}$.

Los episodios de recaídas del daño renal en el primer año del trasplante, pueden predecir quiénes tienen mayor riesgo para cáncer de piel, posiblemente porque requieren más dosis de inmunosupresores ${ }^{41,47}$.

Son varios los mecanismos que llevan a estos pacientes a desarrollar carcinomas de piel, como las mutaciones en el p53, la disminución de células de Langerhans y la infección por el virus del papiloma humano (Human Papilloma Virus, HPV). El ADN del HPV se detecta en 65 a $90 \%$ de los carcinomas espinocelulares en pacientes con trasplante. Los genotipos 1, 2, 3 y 4 son los más frecuentes, pero el HPV 6/11 y el HPV 16/18 tienen mayor potencial oncogénico. Estos genotipos pueden estar presentes en las verrugas de los pacientes con trasplante ${ }^{36,41,42}$.

Por lo anterior, es importante educar a estos pacientes para evitar la exposición solar, usar siempre protector solar y consultar en caso de lesiones sospechosas. En cada consulta de revisión posterior al trasplante, se debe evaluar la piel.

\section{Virus del papiloma humano}

El HPV se ha relacionado con la aparición de carcinomas de piel no melanoma, particularmente en inmunosuprimidos. En reportes de pacientes con alteraciones en la inmunidad celular que presentan 
epidermodisplasia verruciforme, se encuentran altas tasas de transformación maligna de las verrugas atípicas ${ }^{1,28,48}$.

Se estima que $90 \%$ de los carcinomas de piel no melanoma en inmunosuprimidos y $50 \%$ en individuos inmunocompetentes, contienen ADN del HPV ${ }^{1,49}$.

La proteína E6 del HPV causa cambios estructurales en los cromosomas, mientras que la $\mathrm{E} 7 \mathrm{se}$ ha relacionado con anormalidades numéricas (aneuploidías) ${ }^{50}$.

En los carcinomas de piel frecuentemente se detectan mutaciones en el gen $p_{53}$, y secuencias del ADN del HPV. Por lo tanto, queda por establecer si uno o ambos hallazgos son los responsables del inicio de la inestabilidad genómica ${ }^{51}$.

Furslund, et al., evaluaron la presencia de HPV por reacción en cadena de la polimerasa (PCR) en biopsias de 59 pacientes australianos con carcinomas de piel no melanoma y queratosis actínica. El ADN del HPV se encontró en 48 de los 59 pacientes (84\%). Estos autores concluyeron que varios tipos de HPV están presentes en los distintos tipos de carcinomas de piel no melanoma. Sin embargo, el papel de este virus en la patogenia permanece por esclarecerse, puesto que el HPV también se encuentra en la piel sana de estos pacientes ${ }^{52}$.

\section{Sistema inmunitario}

La radiación ultravioleta presente en la luz solar es la primera causa de carcinomas de piel no melanoma. La radiación ultravioleta provoca la formación de cataratas, las quemaduras solares, el envejecimiento prematuro de la piel, la activación de virus latentes y la supresión inmunitaria; esta última se produce porque hay depresión de la respuesta inmunitaria mediada por células. Además, la radiación ultravioleta disminuye la capacidad de responder frente a microorganismos infecciosos ${ }^{53}$.

La radiación ultravioleta causa supresión del sistema inmunitario, disminuyendo la vigilancia sobre las células tumorales; los sistemas experimentales consideran que en parte se debe al ácido urocánico. La radiación UVB solo penetra las primeras capas de la piel, por lo que se postula que debe existir un fotorreceptor en las capas más superficiales de la piel que pueda ser activado por la radiación ultravioleta y envíe señales para una inmunosupresión ${ }^{54}$.

Desde hace muchos años se conoce la relación que tiene el cáncer con el sistema inmunitario. En 1967, Burnett introdujo el concepto de "inmunovigilancia"; esta idea se basa en el concepto que un sistema inmunitario intacto reconoce activamente y controla las células tumorales, y cuando esta vigilancia inmunitaria falla, se desarrollan los carcinomas ${ }^{55}$.

Los datos experimentales sugieren que el ADN y el ácido urocánico alterados actúan como fotorreceptores importantes para la inmunosupresión y la producción del cáncer. La histidina amoniaco-liasa (HAL, histidasa) provocan el catabolismo del aminoácido L-histidina a ácido urocánico trans, que a continuación se acumula en las capas más superficiales de la piel. Con la exposición a la radiación UVB, el ácido urocánico se isomeriza a la forma cis-, el cual imita los efectos de la inmunodepresión UVB, tanto in vitro como in vivo, afectando la presentación de antígenos tumorales por las células de Langerhans y mediando la liberación de neuropéptidos, histamina y citocinas, como las IL-1 e IL-10 ${ }^{55}$.

Welsh, et al., evaluaron el gen $H A L I 439 \mathrm{~V}$ y el polimorfismo genético de la histidasa (rs7297245) en el carcinoma basocelular y en el carcinoma espinocelular. Sus estudios sugieren que la exposición intensa a la radiación ultravioleta aumenta el riesgo de carcinomas de piel no melanoma en presencia de esta variante alélica ${ }^{56}$.

Los mastocitos también participan en la inmunosupresión mediada por la radiación ultravioleta. En estudios en ratones knockout sobre mastocitos, los cuales se suprimen con radiación ultravioleta, los ratones se recuperan de la inmunosupresión después de aplicarles mastocitos derivados de médula ósea de cepas salvajes. El proceso exacto por el que los mastocitos contribuyen a la inmunosupresión no se conoce. Además, la densidad de los mastocitos en la piel de los humanos se ha correlacionado con la propensión para ambos tipos de cáncer de piel, melanoma y no melanoma. Muchos mediadores de la inflamación liberados por los mastocitos, incluyendo la histamina, la prostaglandina E2, la serotonina, el factor activador de plaquetas (PAF), el TNF, la IL-4 y la IL-10, son mediadores críticos de la inmunosupresión inducida por la radiación ultravioleta ${ }^{16}$.

Byrne, et al., demostraron que la exposición a la radiación ultravioleta desencadena la migración de los mastocitos a los ganglios linfáticos, efecto que es mediado por la expresión de receptores de quimiocinas CXCR4 en los mastocitos y CXCL12 en los ganglios. El bloqueo de la migración de los mastocitos con antagonistas de CXCR4, revierte la inmunosupresión mediada por la radiación ultravioleta ${ }^{57}$.

Otro de los efectos importantes de la radiación ultravioleta se produce sobre las células de Langerhans. La radiación UVB disminuye el número de antígenos y la capacidad de presentarlos; además, induce la producción de IL-10. En algunos reportes se ha demostrado que bajas dosis de radiación UVB disminuyen la expresión de las moléculas del complejo mayor de histocompati- 
bilidad (MHC) de clase II, lo que se traduce en menor capacidad de presentación antigénica. Después de una quemadura grave, las células de Langerhans son reemplazadas por precursores derivados de la médula ósea y por células dendríticas que migran de los folículos pilosos, las cuales tienen deficiencia parcial de MHC II y moléculas coestimuladoras, importantes para la activación de los linfocitos T. Todo lo anterior hace que se altere la vigilancia inmunitaria y se permita el desarrollo de tumores ${ }^{16,58}$.

\section{Conclusión}

El cáncer de piel es uno de los tumores más frecuentes; sin embargo, tiene subregistro por su baja mortalidad. Entre los factores de riesgo, el principal es la exposición a la radiación ultravioleta, principalmente UVB. Su incidencia está en aumento debido a la exposición al sol, el uso de cámaras bronceadores, el aumento de los trasplantes y la mayor supervivencia de los pacientes con trasplante. Su patogénesis involucra aspectos como la resistencia a la apoptosis, las mutaciones del gen p53, la vía del hedgehog, la infección por el HPV, los radicales libres de oxígeno y la inmunosupresión. Estos factores no son excluyentes y su estudio brinda oportunidades para el desarrollo de herramientas de detección de personas predispuestas y de nuevos medicamentos que prevengan o detengan la progresión de la enfermedad.

\section{Agradecimientos}

Al Dr. Peter Erb del Institute for Medical Microbiology, Universidad de Basel, Switzerland, por permitirme publicar la TABLA 3, que aparece en su artículo, "Role of apoptosis in basal cell and squamous cell carcinoma formation"

\section{Referencias}

1. Madan V, Lear JT, Szeimies R-M. Non-melanoma skin cancer. The Lancet. 2010;375:673-85.

2. Albert MR, Weinstock $M$ a. Keratinocyte Carcinoma. CA: A Cancer Journal for Clinicians. 2003 Sep;53:292-302.

3. Gutierrez R. Cáncer de piel. facultad de medinicina UNAM. 2003;46:165-71.

4. Erb P, Ji J, Wernli M, Kump E, Glaser A, Büchner S A. Role of apoptosis in basal cell and squamous cell carcinoma formation. Immunology letters. 2005;100:68-72.

5. Cohen JL. Acinic Keratosis Treatment as a Key Component of Preventive Strategies for Nonmelanoma Skin Cancer. Dermatology. 2010;3:39-44.

6. Rubin AI, Chen EH, Ratner D. Basal-cell carcinoma. The New England journal of medicine. 2005 Nov;353:2262-9.
7. Tilli C.M.L.J, Van Steensel M.A. M, Krekels G.A. M, Neumann H.A. M, Ramaekers F.C.S. Molecular aetiology and pathogenesis of basal cell carcinoma. The British journal of dermatology. 2005;152:1108-24.

8. Heal CF, Raasch B A, Buettner PG, Weedon D. Accuracy of clinical diagnosis of skin lesions. The British journal of dermatology. 2008;159:661-8.

9. Pardo C, Murillo R, Piñeros M, Castro MA. Casos Nuevos de Cáncer en el Instituto Nacional de Cancerología, Colombia, 2002. Revista Colombiana de cancerología. 2003;7:4-19.

10. San Clemente G.Mahecha M, Guzmán C. Enfermedades de la piel más frecuentes en consulta externa dermatológica del Hospital Universitario San Vicente de Paúl y del Hospital Infantil, Medellín,1999. Acta Medica Colombiana. 2001;26:240-4.

11. Sanchez G, Nova J, Arias N. Prácticas frente a la radiación ultravioleta y características epidemiológicas de un grupo de pacientes con carcinoma basocelular en un centro de referencia nacional en Colombia. Revista Colombiana de Cancerología. 2010;14:144-51.

12. Velasquez, M Zuluaga A. Primera jornada de detección precoz del cáncer de piel , Asocolderma 2011 , reporte de la experiencia en Medellín, Colombia. Revista Asociación Colombiana de Dermatología. 2012;20:135-46.

13. Restrepo JC, Zuluaga A, Ochoa FL, Jiménez SB, Castaño OL, Uribe C, et al.. Jornada de prevención y detección de cáncer de piel en personas mayores de 18 años. Medellín, mayo de 2005. Universidad del CES. Revista CES Medellín. 2009;23:93-103.

14. Parkin DM, Pisani P, Ferlay J. Global Cancer Statistics, 2002. CA: a cancer journal for clinicians. 1999;49: 33-64.

15. Schulman JM, Fisher DE. Indoor UV tanning and skin cancer: helth risks and opportunities. Curr Opin Oncol . 2009;21:144-49.

16. Meunier L. Ultraviolet light and dendritic cells. European journal of dermatology. 1999 Jun;9:269-75.

17. Fortina AB, Piaserico S, Caforio ALP, Abeni D, Alaibac M, Angelini $\mathrm{A}$, et al. Immunosuppressive level and other risk factors for basal cell carcinoma and squamous cell carcinoma in heart transplant recipients. Archives of dermatology. 2004;140:1079-85.

18. Fitzpatrick TB, Wolff K, Goldsmith LA, Katz SI, Gilchrest BA, Paller SA . Carcinogenesis. Fitzpatrick's dermatology in general medicine. Seventh Edition, Mc Graw Hill Medical,2008. 977-9

19. Alam M, Ratner D. Cutaneous squamous-cell carcinoma. The New England Journal of Medicine. 2001;344:975-83.

20. Ridley AJ, Whiteside JR, McMillan TJ, Allinson SL. Cellular and sub-cellular responses to UVA in relation to carcinogenesis. International Journal of Radiation Biology. 2009;85:177-95.

21. Freeman SE, Hacham H, Gange RW, Maytum DJ, Sutherland JC, Sutherland BM. Wavelength dependence of pyrimidine dimer formation in DNA of human skin irradiated in situ with ultraviolet light. Proceedings of the National Academy of Sciences of the United States of America. 1989;86:5605-9.

22. Epstein EH. Basal cell carcinomas: attack of the hedgehog. Nature reviews. Cancer. 2008 Oct;8:743-54.

23. Wetmore C. Sonic hedgehog in normal and neoplastic proliferation. Currenet opinion in genetics and devolpment. 2003;13:34-42.

24. Soufir N, Gerard B, Portela M, Brice A, Liboutet M, Saiag P, et al. PTCH mutations and deletions in patients with typical nevoid basal cell carcinoma syndrome and in patients with a suspected genetic predisposition to basal cell carcinoma: a French study. British journal of cancer. 2006;95:548-53.

25. Bürglin TR. The Hedgehog protein family. Genome Biology. 2008 Jan;9:241. 
26. Tang JY, So PL, Epstein Jr. EH Novel Hedgehog pathway targets against Basal Cell Carcinoma. Toxicol Appl Pharmacol. 2007;224:257-64.

27. Danaee H, Karagas MR, Kelsey KT, Perry AE, Nelson HH. Allelic loss at Drosophila patched gene is highly prevalent in Basal and squamous cell carcinomas of the skin. The Journal of investigative dermatology. 2006;126(5):1152-8.

28. de Zwaan SE, Haass NK. Genetics of basal cell carcinoma. The Australasian Journal of Dermatology. 2010;51:81-92; quiz 93-4.

29. Kumar V, Abbas AK, Fausto N, Mitchell RN.The Skin Tumors. Robbins Basic Patology. 8 $^{\text {th }}$ Edition, Elsevier 2007. 848-59

30. Rosenstein BS, Phelps RG, Weinstock MA, Bernstein JL, Gordon ML, Rudikoff D, et al. p53 mutations in basal cell carcinomas arising in routine users of sunscreens. Photochemistry and Photobiology. 1999; 70. 798-806.

31. Stratigos A J, Kapranos N, Petrakou E, Anastasiadou A, Pagouni A, Christofidou E, et al. Immunophenotypic analysis of the p53 gene in non-melanoma skin cancer and correlation with apoptosis and cell proliferation. Journal of the European Academy of Dermatology and Venereology : JEADV. 2005;19:180-6.

32. Kelley KW. $p 53$ and the Pathogenesis of Skin Cancer. Brain, behavior, and immunity. 2008;22:629.

33. Manestar-Blazic T, Batinac T, Hadzisejdic I, Brajac I. Apoptosis and immune response are responsible for the site-specific incidence of non-melanoma skin cáncer. Medical hypotheses. 2007;68:853-5.

34. Kirkin V, Joos S, Zörnig M. The role of Bcl-2 family members in tumorigenesis. Biochimica Biophysica Acta. 2004;1644:229-49.

35. Abbas AK, Lichtman AH, Sillai S. Inmunity to tumors. Cellular and molecular immunonology, 7 edition.Elsevier 2012,389-404

36. Manestar-Blazic T, Batinac T, Hadzisejdic I, Brajac I. Apoptosis and immune response are responsible for the site-specific incidence of non-melanoma skin cancer. Medical hypotheses. 2007;68:853-5.

37. Sjöström J, Bergh J. How apoptosis is regulated, and what goes wrong in cancer. British Medical Journal. 2001;322:1538-9.

38. Venereo JR. Daño Oxidativo, Radicales Libres y Antioxidantes. Revista Cubana de medicina militar. 2002;31:126-33.

39. Griffiths HR, Mistry P, Herbert KE, Lunec J. Molecular and Cellular Effect of Ultraviolet Light-Induced Genotoxicity. Critical Reviews in Clinical Laboratory Sciences. 1998;35:189-237.

40. Euvrard S K. skin cancers in kidney and heart transplant recipients after the first squamous cell carcinoma. Transplantation. 2006;81:1093-100.

41. Euvrard S, Kanitakis J, Claudy A. Skin cancers after organ transplantation. The New England journal of medicine. 2003;348:1681-91.

42. Dreno B. Skin cancers after transplantation. Nephrology Dialysis Transplantation. 2003;18:1052-8.

43. Moloney FJ, Almarzouqi E, O’Kelly P, Conlon P, Murphy GM. Sunscreen use before and after transplantation and assessment of risk factors associated with skin cancer development in renal transplant recipients. Archives of dermatology. 2005;141:978-82.
44. Tiu J, Li H, Rassekh C, Van der Sloot P, kovach R, Zhang P. Molecular basis of posttransplant squamous cell carcinoma: the potential role of cyclosporine a in carcinogenesis. The laryngoscope. 2006;106:762-9.

45. Maddox JS, Soltani K. Risk of nonmelanoma skin cancer with azathioprine use. Inflammatory bowel diseases . 2008;14:1425-31.

46. España A, Martínez-González M A, García-Granero M, SánchezCarpintero I, Rábago G, Herreros J. A prospective study of incident nonmelanoma skin cancer in heart transplant recipients. The Journal of investigative dermatology. 2000;115:1158-60.

47. Caforio a L, Fortina a B, Piaserico S, Alaibac M, Tona F, Feltrin $\mathrm{G}$, et al. Skin cancer in heart transplant recipients: risk factor analysis and relevance of immunosuppressive therapy. Circulation. 2000;102(19 Suppl III):III222-7.

48. Harwood C A, McGregor JM, Proby CM, Breuer J. Human papillomavirus and the development of non-melanoma skin cancer. Journal of clinical pathology. 1999;52:249-53.

49. Asgari MM, Kiviat NB, Critchlow CW, Stern JE, Argenyi ZB, Raugi GJ, et al. Detection of human papillomavirus DNA in cutaneous squamous cell carcinoma among immunocompetent individuals. The Journal of investigative dermatology. 2008;128:1409-17.

50. Hashida T, Yasumoto S. Induction of chromosome abnormalities in mouse and human epidermal keratinocytes by the human papillomavirus type 16 E7 oncogene. The Journal of general virology. 1991;72:1569-77.

51. Boukamp P. Non-melanoma skin cancer: what drives tumor development and progression? Carcinogenesis. 2005;26:1657-67.

52. Forslund O, Ly H, Reid C, Higgins G. A broad spectrum of human papillomavirus types is present in the skin of Australian patients with non-melanoma skin cancers and solar keratosis. British journal of dermatology. 2003;149:64-73.

53. Nghiem DX, Kazimi N, Clydesdale G, Ananthaswamy HN, Kripke ML, Ullrich SE. Ultraviolet a radiation suppresses an established immune response: implications for sunscreen design. The Journal of investigative dermatology. 2001 Nov;117:1193-9.

54. Walterscheid JP, Nghiem DX, Kazimi N, Nutt LK, Mcconkey DJ, Norval M, et al. Cis-urocanico, a sunligth-induced factor immunosuppressive, activates immune suppression via the 5 - $\mathrm{HT} 2 \mathrm{~A}$ receptor. 2006; 103:17420-25

55. Burnet M. Concepts of autoimmune disease and their implications for therapy. Perspect Biol Med. 1967;10:14-51.

56. Welsh MM, Karagas MR, Applebaum KM, Spencer SK, Perry AE, Nelson HH. A role for ultraviolet radiation immunosuppression in non-melanoma skin cancer as evidenced by gene-environment interactions. Carcinogenesis. 2008;29:1950-4.

57. Byrne SN, Limón-Flores AY, Ullrich SE. Mast cell migration from the skin to the lymph nodes upon UV-irradiation reprents a key step in the induction of immune supression. The Journal of Immunology. 2008;180:4648-55.

58. Morison WL, Bucana C, Kripke ML. Systemic suppression of contact hypersensitivity by UVB radiation is unrelated to the UVB-induced alterations in the morphology and number of Langerhans cells. Immunology. 1984;52:299-306. 